\title{
Intercalations and Characterization of Zinc/Aluminium Layered Double Hydroxide-Cinnamic Acid
}

\author{
Nurain Adam ${ }^{1,2}$, Sheikh Ahmad Izaddin Sheikh Mohd Ghazali ${ }^{*}$, Nur Nadia Dzulkifli², Cik \\ Rohaida Che Hak ${ }^{3}$, Siti Halimah Sarijo ${ }^{1}$ \\ ${ }^{1}$ Faculty of Applied Sciences, Universiti Teknologi MARA, 40450, Shah Alam, Malaysia \\ ${ }^{2}$ Faculty of Applied Sciences, Universiti Teknologi MARA, Pekan Parit Tinggi, 72000, Kuala Pilah, \\ Negeri Sembilan, Malaysia \\ ${ }^{3}$ Material Technology Group, Industrial Technology Division, Malaysian Nuclear Agency, Kajang, \\ Malaysia
}

Received: $1^{\text {st }}$ October 2018; Revised: $8^{\text {th }}$ December 2018; Accepted: $12^{\text {nd }}$ December 2018; Available online: 25th January 2019; Published regularly: April 2019

\begin{abstract}
Cinnamic acid (CA) is known to lose its definite function by forming into radicals that able to penetrate into the skin and lead to health issues. Incorporating CA into zinc/aluminum-layered double hydroxides (Zn/Al-LDH) able to reduce photodegradation and eliminate close contact between skin and CA. Co-precipitation or direct method used by using zinc nitrate hexahydrate and aluminium nitrate nonahydrate as starting precursors with addition of various concentration of $\mathrm{CA}$. The $\mathrm{pH}$ were kept constant at $7 \pm 0.5$. Fourier Transform Infrared-Attenuated Total Reflectance (FTIR-ATR) shows the presence of nanocomposites peak $3381 \mathrm{~cm}^{-1}$ for OH group, $1641 \mathrm{~cm}^{-1}$ for $\mathrm{C}=\mathrm{O}$ group, $1543 \mathrm{~cm}^{-1}$ for $\mathrm{C}=\mathrm{C}$ group and $1206 \mathrm{~cm}^{-1}$ for $\mathrm{C}-\mathrm{O}$ group and disappearance of $\mathrm{N}-\mathrm{O}$ peak at $1352 \mathrm{~cm}^{-1}$ indicates that cinnamic acid were intercalated in between the layered structures. Powder X-Ray Diffraction (PXRD) analysis for $\mathrm{Zn} / \mathrm{Al}-\mathrm{LDH}$ show the basal spacing of $9.0 \AA$ indicates the presence of nitrate and increases to $18.0 \AA$ in basal spacing in $0.4 \mathrm{M} \mathrm{Zn/Al-LDH-CA}$. CHNS analysis stated that $40 \%$ of cinnamic acid were being found and intercalated in between the interlayer region of the $\mathrm{Zn} / \mathrm{Al}-\mathrm{LDH}$ with higher thermal stability. Field Emission Scanning Electron Microscope (FESEM) images of $0.4 \mathrm{M} \mathrm{Zn/Al-LDH-CA}$ shows that the nanocomposites are in more compact, flaky non porous, large agglomerates with smooth the surfaces of the intercalated compound. Controlled release was successful with $80 \%$ release in phosphite anion and $70 \%$ release carbonate anion. The cinnamic acid was successfully inserted between the interlayer regions of $\mathrm{Zn} / \mathrm{Al}-\mathrm{LDH}$ with slow release formulation. Copyright $\mathbb{C}$ 2019 BCREC Group. All rights reserved
\end{abstract}

Keywords: Layered double hydroxide; cinnamic acid; co-precipitation; intercalation; sunscreen agent

How to Cite: Adam, N., Ghazali, S.A.I.S.M., Dzulkifli, N.N., Hak, C.R.C., Sarijo, S.H. (2019). Intercalations and Characterization of Zinc/Aluminium Layered Double Hydroxide-Cinnamic Acid. Bulletin of Chemical Reaction Engineering \& Catalysis, 14 (1): 165-172 (doi:10.9767/bcrec.14.1.3328.165-172)

Permalink/DOI: https://doi.org/10.9767/bcrec.14.1.3328.165-172

\section{Introduction}

Sun play a major role in providing essential vitamin $\mathrm{D}$ towards human. This happen when a UVB radiation hit the skin surfaces are being converted to previtamin D3 by the cholesterol

\footnotetext{
* Corresponding Author.

E-mail: sheikhahmadizaddin@ns.uitm.edu.my

(S.A.I.S.M. Ghazali)
}

Telp: +6017-2426828, Fax: +606-4842449 found in the skin are metabolize in liver into hydroxyvitamin D and turn into the useable Vitamin D in the kidneys [1]. However, excessive exposure of sun radiation could affect human health such as sun tanning, sunburn and sometimes lead to risky issues such as skin cancers [2]. Thus, researchers and industries have making a great effort concerning human health issues regarding sun exposure. 
Organic compound, such as: cinnamic acid (CA) that used in sunscreen agents, have greatly promoted in the cosmetics industry, generally to serve the purpose of protecting human skin from direct exposure of sunlight. However, these organic compounds lose their functions, causes photoirradiation and cause health problems when using in high concentrations [3]. It also able to enter human skin and disrupted the biological condition of human health. Exposure of sunlight on these agents cause to undergoes decomposition, induce phototoxic contact dermatitis and photocross reaction when interact with other molecules [4]. Thus, incorporating organic anions, cinnamate, into the two dimensional layered double hydroxides could solve the problems.

Layered double hydroxides (LDHs) resembles the brucite-like layers $(\mathrm{MgOH})$ usually containing divalent and trivalent metallic cation with the chemical formula $\left[\mathrm{M}^{2+}{ }_{1-}\right.$ $\left.{ }_{\mathrm{x}} \mathrm{M}^{3+}{ }_{\mathrm{x}}(\mathrm{OH})_{2}\right]\left[\mathrm{A}^{\mathrm{n}}-\right]_{\mathrm{x} / \mathrm{n} .} \mathrm{zH} \mathrm{H}_{2} \mathrm{O}$., where, $\mathrm{M}^{2+}$ is the divalent cation, such as: $\mathrm{Mg}^{2+}, \mathrm{Zn}^{2+}$ or $\mathrm{Ni}^{2+}, \mathrm{M}^{3+}$ is the trivalent cation, such as: $\mathrm{Al}^{3+}, \mathrm{Mn}^{3+}$ and $\mathrm{Fe}^{3+}, \mathrm{A}^{\mathrm{n}}$ - is the counter anion, such as: $\mathrm{C}_{9} \mathrm{H}_{7} \mathrm{O}_{2}$ (cinnamate), $\mathrm{CO}_{3}{ }^{2-}, \mathrm{NO}_{3}{ }^{-}$or $\mathrm{Cl}^{-}$and $x$ is the molar ratio of $\mathrm{M}^{2+} /\left(\mathrm{M}^{2+}+\mathrm{M}^{3+}\right)[5,6]$. These layered double hydroxides play a great role since it have high stability, able to acts as protective barrier and able to absorb high UV radiation $[7,8]$.

Various methods have been used to synthesize or intercalated the guest anion into the layered host such as urea hydrolysis, reconstruction method and ion-exchange method [9]Co-precipitation method or direct method are one of the method and being used in this study to insert the cinnamate anions (CA-) into the interlayered region of zinc/aluminium-LDH $(\mathrm{Zn} / \mathrm{Al}-\mathrm{LDH})$ since it is able to be produced in high quantity, safe and not costly. Purpose of choosing $\mathrm{Zn} / \mathrm{Al}$ as the host materials due to $\mathrm{Zn} / \mathrm{Al}-\mathrm{LDH}$ are known to have better UV blocking properties due to increase in particle size and decreased band gap energy compare to $\mathrm{Mg} / . \mathrm{Al}-\mathrm{LDH}$ [10].

The aims of our study are to intercalate the cinnamate anion into the interlayer region $\mathrm{LDH}$ and investigate physiochemical properties of the zinc/aluminium LDH-cinnamic ( $\mathrm{Zn} / \mathrm{Al}$ LDH-CA). To the best of our knowledge, few studies have been done on the release behavior of UV absorber from the LDH interlayer region been reported.

\section{Materials and Methods}

\subsection{Materials}

Cinnamic acid ( $>99 \%$, Sigma), Zinc Nitrate Hexahydrate $(98 \%, R \& M)$, Aluminium Nitrate Nonahydrate (98.5\%, R\&M), Sodium Hydroxide $(99 \%$, R\&M), sodium carbonate $(99.5 \%$, $\mathrm{R} \& \mathrm{M}$ ), sodium dihydrogen phosphite (R\&M, 99.2\%) and deionized water were used.

\subsection{Synthesis}

Co-precipitation or direct method were used to synthesize zinc/aluminium-layered double hydroxides-cinnamic (Zn/Al-LDH-CA) which required the addition of base $(\mathrm{NaOH})$ into the $\mathrm{M}^{2+} / \mathrm{M}^{3+}$ solution that containing the organic anion (CA-) [11]. First, $0.1 \mathrm{M}$ of $\mathrm{Zn}\left(\mathrm{NO}_{3}\right)_{2} .6 \mathrm{H}_{2} \mathrm{O}$ and $0.025 \mathrm{M} \mathrm{Al}\left(\mathrm{NO}_{3}\right)_{3} .9 \mathrm{H}_{2} \mathrm{O}$ were mixed at the ratio of $1: 2$ and were stirred together with 250 $\mathrm{ml}$ of deionized water. Then, $0.4 \mathrm{M}$ and $0.07 \mathrm{M}$ of cinnamic acid solution were added and the $\mathrm{pH}$ was adjusted with slow addition $2 \mathrm{M}$ sodium hydroxide $(\mathrm{NaOH})$ until reach $\mathrm{pH} 7 \pm 0.5$.

The solution must be stirred under influenced of nitrogen gases to avoid carbonate contamination. Then, aging process were taken placed in oil bath shaker for 18 hours at $70{ }^{\circ} \mathrm{C}$ to ensure better precipitate crystallinity. The slurry that obtained were centrifuged and washed with deionized water for three times to remove impurities $\left(\mathrm{Na}^{+}\right.$and $\left.\mathrm{NO}_{3}{ }^{-}\right)$. Once completed, dried the slurry in vacuum oven at 70 ${ }^{\circ} \mathrm{C}$ overnight and kept for further characterization purposes.

\subsection{Characterizations}

Fourier Transform Infrared-Attenuated Total Reflectance (FTIR-ATR) Spectroscopy was recorded from $4000 \mathrm{~cm}^{-1}$ to $400 \mathrm{~cm}^{-1}$ by using Perkin Elmer Spectrum 100 spectrometer. The Powder X-ray diffraction Analysis (PXRD) were recorded from $2^{\circ}$ to $70^{\circ}$ of $2 \theta$ using BRUKER $\mathrm{D} 8$ ADVANCE at $\mathrm{Cu}-\mathrm{K} \alpha$ radiation $(\lambda=1.5418$ $\mathrm{nm}$ ). Thermogravimetric Analysis (TGA) were done by using Ntezsch TG 200 F2 Tarsus under nitrogen gas flow about $50 \mathrm{~mL} / \mathrm{min}$ and heated from room temperature to $1000{ }^{\circ} \mathrm{C}$ with heating rate at $10{ }^{\circ} \mathrm{C} / \mathrm{min}$. Field Emission Scanning Electron Microscopy (FESEM) using ZEISS supra $400 \mathrm{VP}$, where the ample were mounted on carbon tape and excess powder being removed through air blasting. Carbon, hydrogen, nitrogen, and sulphur (CHNS) analysis was done by using CHNS-932 (LECO instrument, USA). The sample was weighed around 1.8 to $3.0 \mathrm{mg}$ using helium as the gas carrier 
and undergoes combustion under high purity oxygen. The sustained released profile were investigated by using $0.1 \mathrm{M} \mathrm{NaCl}$ and $0.1 \mathrm{M} \mathrm{Na}$ $\mathrm{H}_{2} \mathrm{PO}_{3}$, at $275 \mathrm{~nm}$ for 10440 seconds until it reach equilibrium under Perkin Elmer UVSpectroscopy.

\section{Results and Discussion}

\subsection{Fourier Transform Infrared Spectroscopy}

The FTIR-ATR spectra for the intercalated compound were all compared with the $\mathrm{Zn} / \mathrm{Al}$ $\mathrm{LDH}$ spectra and the cinnamic acid spectra. The Zn/Al-LDH from Figure 1a shows the nitrate peaks at $1352 \mathrm{~cm}^{-1}$. The peak at $831 \mathrm{~cm}^{-1}$ indicates the metal-oxygen vibrations happen in between the hydroxides layers and a small band between $607 \mathrm{~cm}^{-1}-733 \mathrm{~cm}^{-1}$ are explaining the M-O stretching modes [12] or due to the the inter-atomic vibration [13]. The broad peak at $3500 \mathrm{~cm}^{-1}$ indicates the presence of water molecules $(\mathrm{OH})$. The presence of the intense peak were due to the stretching mode of the $\mathrm{OH}$ groups in the brucite-like layers and physisorbed as well as the water molecules located between the interlayer region of the LDHs [14].

The important peak in FTIR-ATR spectra that give out recognition for CA functional group are as shown in CA spectra in Figure 1b were $\mathrm{C}-\mathrm{H}$ out of plane bending vibration at 945 $\mathrm{cm}^{-1}$. The CA is a type of aromatic rings with monosubstituents, which can be observed from a sharp peak at $683 \mathrm{~cm}^{-1}$ and sometimes at 710

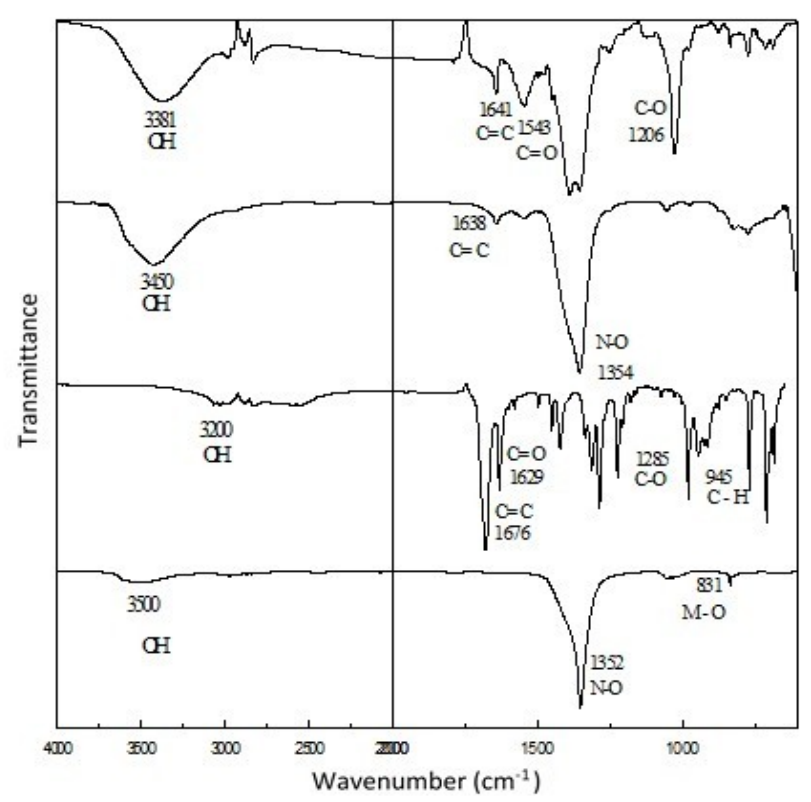

Figure 1. FTIR spectrum for (a) Zn/Al-LDHs, (b) CA, (c) $0.07 \mathrm{M} \mathrm{Zn/Al-LDH-CA}$ and (d) $0.4 \mathrm{M}$ Zn/Al-LDH-CA $\mathrm{cm}^{-1}$. Besides that, the presence of peak at $3200 \mathrm{~cm}^{-1}$ to $2600 \mathrm{~cm}^{-1}$ indicates the presence of $\mathrm{OH}$ group that overlapping with $\mathrm{C}-\mathrm{H}$ absorptions was observed in CA FTIR-ATR spectra. The presence of $\mathrm{C}=\mathrm{O}$ stretching, $\mathrm{C}=\mathrm{C}$ stretching and medium intensity stretching of $\mathrm{C}-\mathrm{O}$ group can be detected at wavenumber 1676,1629 , and 1285. However, the axial deformation of the $\mathrm{C}-\mathrm{H}$ bond of the aromatic rings can be observed at wavenumber of 3200 to 2600 [15].

The important functional group that determines the incorporation of CA into $\mathrm{Zn} / \mathrm{Al}-\mathrm{LDH}$ interlayer region are $\mathrm{C}=\mathrm{C}, \mathrm{C}=\mathrm{O}$, and $\mathrm{C}-\mathrm{O}$ groups. The broad spectra peak in Figure 1c and Figure 1d, between $3300 \mathrm{~cm}^{-1}$ to $3500 \mathrm{~cm}^{-1}$, indicates the presence of $\mathrm{OH}$ stretching. As for Figure 1c, the presence of small peak at 1638 $\mathrm{cm}^{-1}$ which are stretching mode of $\mathrm{C}=\mathrm{C}$ group and the incomplete intercalations due to presence of intense peak at $1354 \mathrm{~cm}^{-1}$, which contribute to stretching vibration of $\mathrm{N}-\mathrm{O}$ $\left(\mathrm{NO}_{3}{ }^{-}\right)$were observed.

Thus, the concentration of CA were increased to $0.4 \mathrm{M}$ and the presence peak at 1641 and $1206 \mathrm{~cm}^{-1}$ in Figure 1(d) spectra indicates the presence of $\mathrm{C}=\mathrm{C}$ stretching and $\mathrm{C}-\mathrm{O}$ stretching were observed. Presence of 3381 $\mathrm{cm}^{-1}$ indicates presences of water at the interlayer and intralayer region of LDHs. Besides that, the peak at $1352 \mathrm{~cm}^{-1}$ that at first could be observed in FTIR spectrum of LDH-Host were disappear from the FTIR-ATR spectrum

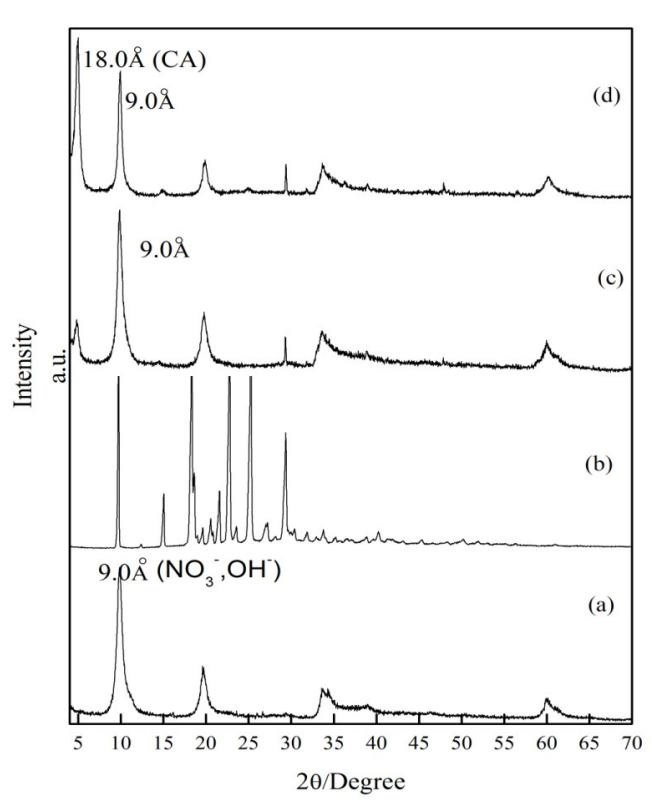

Figure 2. XRD pattern for (a) Zn/Al-LDH, (b) $\mathrm{CA}$, (c) $0.07 \mathrm{M} \mathrm{Zn/Al-LDH-CA}$ and (d) $0.4 \mathrm{M}$ Zn/Al-LDH-CA 
of 0.4 M LDH-CA. This shows that the incorporation of cinnamate anion in between the $\mathrm{LDHs}$ was completely happened when the concentration of CA were increase up to $0.4 \mathrm{M}$. The effects of concentration influence the intercalation process of $\mathrm{CA}$ into the $\mathrm{Zn} / \mathrm{Al}-\mathrm{LDH}$ where it need a certain amount of anion to replaced nitrate which first existed in the interlayer of $\mathrm{LDH}$. The observed wavenumber of the intercalated compound were shifted to the lower region in the spectra. These phenomenona happen due to the electrostatic interaction between the organic anion (guest) and the inorganic layered structure of the LDH (host) [16].

\subsection{Powder X-Ray Diffraction Analysis}

Formation of 4 sharp peaks in symmetrical manner in the XRD pattern of $\mathrm{Zn} / \mathrm{Al}-\mathrm{LDH}$ as shown in Figure 2. This indicates that the LDH precursors are in bioinorganic network [11], with the calculated basal spacing using Bragg's Law formula was $9.0 \AA$ which determines the presence of nitrates that corresponded to the sum of the thickness of the anions, $\mathrm{NO}_{3^{-}}$and the brucite like layers sheets of the layered compound [17].

Once the incorporation of organic anion into the interlayer region of the LDH show increases in basal spacing which indicates that occurring entrapment and replacement of anion takes placed. Furthermore, the Bragg reflections were shifted to the lower angle region due to intercalation of the organic anions decreases the crystallinity of the LDHs [18]. This can be seen through the XRD pattern of $0.07 \mathrm{M}$ of Zn/Al-CA from Figure 2, when $0.07 \mathrm{M}$ of cinnamic acid being introduced into the LDHs interlayer region. The presence of new peak at lower region of XRD pattern was observed. This shows that the intercalation process has taken placed when using 0.07 M CA. However, the presence of co-intercalation of guest anion and the nitrate existed in between the interlayer spacing corresponded to the FTIR spectrum were observed. Thus, concentration of organic anion should be increases in order for it to replace the nitrate ions completely.

When the concentration of cinnamate anion increases up to $0.4 \mathrm{M}$, the basal spacing increases from $9.0 \AA$ to $18.0 \AA$, concludes that the cinnamate was presence in between the interlayer region of the LDHs. This to the topotactic ion exchange reaction [19] between the cinnamate from the solution and the nitrate in the interlayer region in gaining the enthalpy and entropy [20] causes the cinnamate to replaced nitrate position. This explains the increases in basal spacing of the LDHs before and after the interleave process of cinnamate anion takes placed in between the LDHs region. The presence of intense and sharper peaks at $5^{\circ}$ observes in $0.4 \mathrm{M} \mathrm{Zn/Al-LDH-CA}$ from Figure 2 concludes that the hybrid materials (Zn/AlLDH-CA) were well intercalated with high crystallinity [21].

\subsection{Spatial Orientation and Molecular Struc- ture}

Based on the basal spacing of the intercalated compound, the gallery height of interlayer region of the $\mathrm{Zn} / \mathrm{Al}-\mathrm{LDH}$ that preoccupied with CA- anions is $13.2 \AA$, when subtracted the layer thickness of the Zn/Al-LDH (4.8 A) [22]. Assuming from the molecular structure and charge orientation of the cinnamate anion, the anion were consider to orientated in bilayer arrangements in between the interlayer region of the $\mathrm{LDH}$ as the interlayer space are much
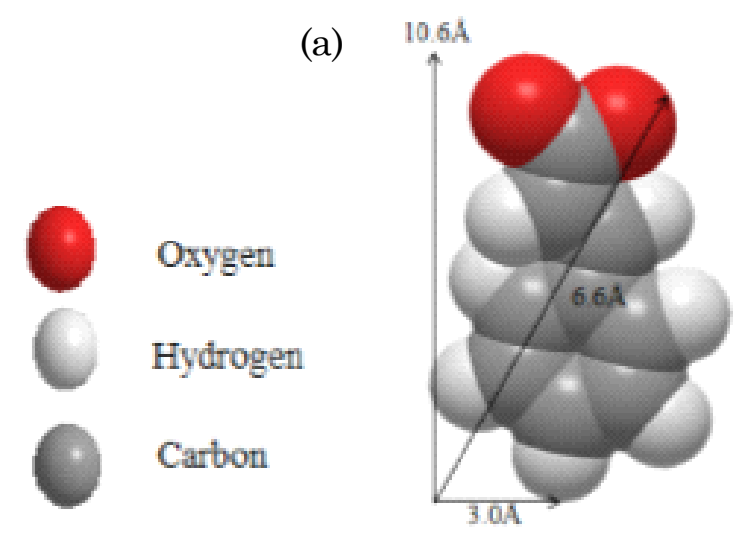

(b)

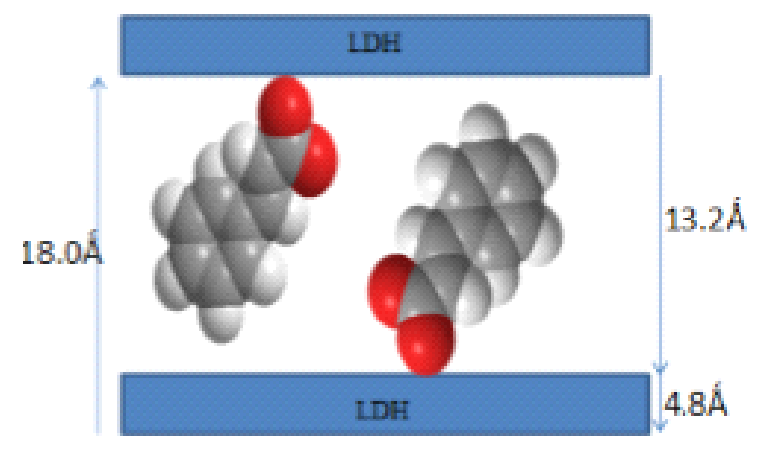

Figure 3. Illustration on (a) molecular structure of CA and (b) Spatial orientation of CA in between the LDH interlayer region 
more bigger than the anion size, where the functional group of carboxylate were facing the hydroxide layers as shown in Figure 3b. Figure 3 shows the illustration on the molecular structure and the proposed spatial orientation of $\mathrm{CA}$ - intercalated in between the $\mathrm{Zn} / \mathrm{Al}-\mathrm{LDH}$.

\subsection{Thermogravimetric Analysis}

The thermal behavior of the nanocomposites and the host were investigated by using thermogravimetric and differential thermogravimetric analysis as shown in Figure 4. Thermal decomposition of pure cinnamic acid (Figure 4a) happened at maximum temperature of 210 ${ }^{\circ} \mathrm{C}$ with $99.7 \%$ weight loss. The thermal decomposition of the inorganic host, $\mathrm{Zn} / \mathrm{Al}-\mathrm{LDH}$ as shown in Figure $4 b$, exist two exothermic reactions. The first decomposition happen at $127{ }^{\circ} \mathrm{C}$ with $7.5 \%$ weight loss that can be diagnose as the removal of the physisorbed water at the internal and external of the LDH structures The
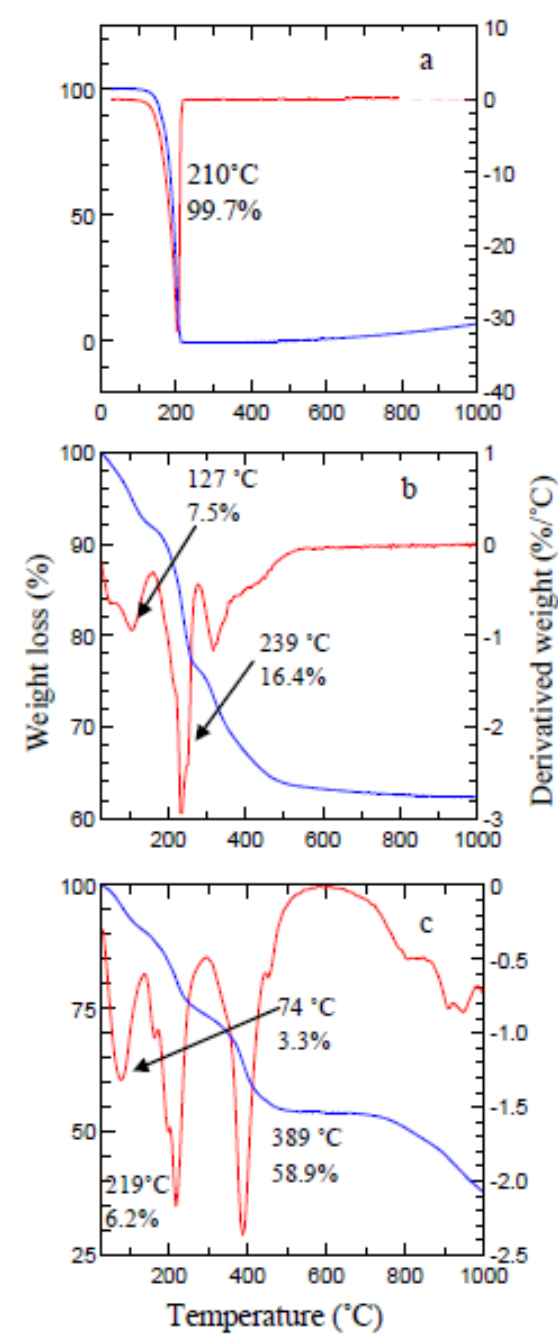

Figure 4. TGA/DTG thermogram for (a) CA, (b) Zn/Al-LDH and (c) $0.4 \mathrm{M} \mathrm{Zn/Al-LDH-CA}$ second exothermic reaction indicate that the process of dihydroxylation of the metal oxides and decomposition of the nitrate ions $[15,16]$, at maximum temperature of $239{ }^{\circ} \mathrm{C}$ with 16.4 $\%$ weight loss.

Comparisons on decomposition temperature were made between the pure CA, Zn/Al-LDH and intercalated compound. The intercalated compounds were observed to achieve three stages of exothermic reactions as shown in Figure 4c. First exothermic reaction indicates the decomposition at temperature of $74{ }^{\circ} \mathrm{C}$ with weight loss $3.3 \%$ indicates the removal of water or moisture in the interlayer region. The next thermal decomposition happens at $219{ }^{\circ} \mathrm{C}$ with $6.2 \%$ weight loss indicates the removal of interlayer anion and the dihydroxylation of the $\mathrm{OH}^{-}$layer. Last stages exothermic reactions occur at $389{ }^{\circ} \mathrm{C}$ with $58.9 \%$ weight loss. The third exothermic reactions lead to the major decomposition on the organic moiety leaving only less volatile metal oxide [16], which in this study is the zinc oxide and aluminium oxide comes from the layered structure of hydroxides. The TGA/DTG data which are correspondence with the FTIR data indicates that the nanocomposites form are not simply the mixture of two different compound but a strong supramolecular interactions (electrostatic attractions between opposite charges, H-bond and van der Waals force) between the guest anion and host layers [23].

3.5 Carbon, Hydrogen, Nitrogen, and Sulphur Analysis

The percentage of Carbon and Hydrogen increase up to $29.4 \%$ and $15.3 \%$ indicates the presence of the intercalated organic anion as shown in Table 1. The total percentage loading of cinnamate anion being intercalated in between the interlayer region of the LDHs was calculated to be $40 \%$. The polarity of the guest anion, the surface charge density and unoccupied interlayer space were the reasons that affect the values of the percentage loading [24]. Although the percentage of nitrogen decreases

Table 1. CHNS percentage for $\mathrm{Zn} / \mathrm{Al}-\mathrm{LDH}$ and $0.4 \mathrm{M} \mathrm{Zn} / \mathrm{Al}-\mathrm{LDH}-\mathrm{CA}$

\begin{tabular}{lcccc}
\hline & $\begin{array}{c}\mathrm{C} \\
(\%)\end{array}$ & $\begin{array}{c}\mathrm{H} \\
(\%)\end{array}$ & $\begin{array}{c}\mathrm{N} \\
(\%)\end{array}$ & $\begin{array}{c}\mathrm{S} \\
(\%)\end{array}$ \\
\hline 0.4 M Zn/Al-LDH-CA & 29.4 & 15.3 & 1.8 & nd \\
Zn/Al-LDH & nd & 0 & 3.00 & nd \\
\hline
\end{tabular}


from $3 \%$ to $1.8 \%$, there are $1.2 \%$ of nitrate that still exist in between the interlayer region which are correspondent with PXRD results that show presence of nitrate at $9.0 \AA$ in $0.4 \mathrm{M}$ $\mathrm{Zn} / \mathrm{Al}-\mathrm{LDH}$.

\subsection{Microscopic Morphology}

FESEM images for $\mathrm{Zn} / \mathrm{Al}-\mathrm{LDH}$ as shown in Figure 5(a) represents the stacking of plate-like sheets with sharp edges. Meanwhile, after intercalations with $0.4 \mathrm{M}$ cinnamate anions, the surfaces of the intercalated compound show much more compact, flaky non porous large agglomerates surfaces (Figure 5(b)).

\subsection{Sustained Release Behaviour}

Two types of salt anions were used, which are $0.1 \mathrm{M}$ sodium chloride and $0.1 \mathrm{M}$ sodium dihydrogen phosphate to investigate the effect anions salts towards the de-intercalations of $\mathrm{CA}$ out of the interlayer region of the LDH structure. The ability of the LDH structure to undergoes de-intercalation process are due the
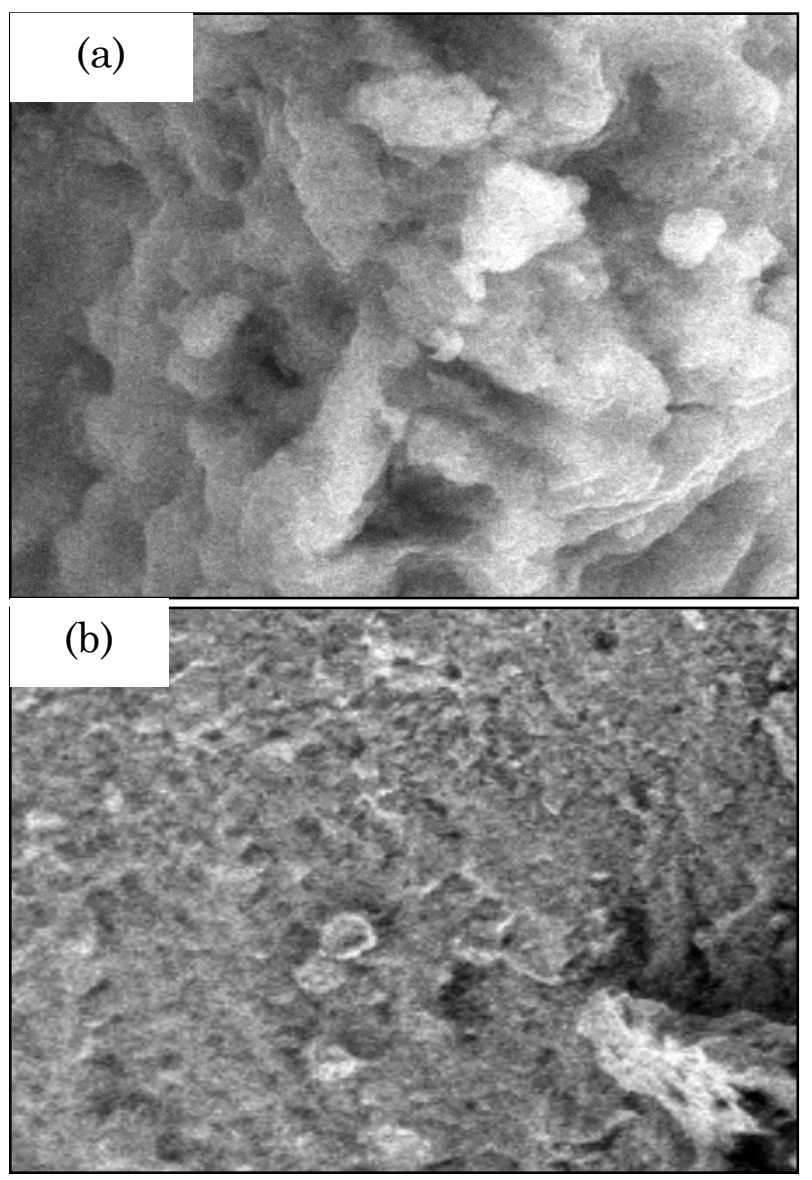

Figure 5. FESEM images for (a) $\mathrm{Zn} / \mathrm{Al}-\mathrm{LDH}$ at $1.00 \mathrm{KX}$ and (b) $0.4 \mathrm{M} \mathrm{Zn/Al-LDH} / \mathrm{CA}$ at $3.00 \mathrm{~K}$ ion exchange process causes the intercalated CA to be able to removed out from the interlayer region, thus forming a new type of nanocomposites. Figure 6 shows the illustration of the formation of new type of nanocomposites thru ion exchange process.

Based on Figure 7, the presences of "burst effect" were observed 100 seconds and 399 second for carbonate salts solutions and phosphite salts solutions at the beginning of the release profile. Bursting effect happen due to the burst release of the CA adsorbed on the LDHs surfaces. The percentage release of CA out from the LDH layer by using salts anion containing $\mathrm{PO}_{3}{ }^{3-}$ and $\mathrm{CO}_{3}{ }^{2-}$ are $80 \%$ and $70 \%$. The percentage release using $\mathrm{PO}_{3}{ }^{3-}$ were higher compare to the $\mathrm{CO}_{3}{ }^{2-}$, This happen due the rate of exchange ability increases as the increasing affinity and decreasing in ionic radius causes the curve for $\mathrm{PO}_{3}{ }^{3-}$ much more higher compare to the $\mathrm{CO}_{3}{ }^{2-}$ [24]. Furthermore, the higher electrostatic interaction between phosphate anions and the interlayers region of the $\mathrm{LDHs}$ structure also causes the release of CA under phos-

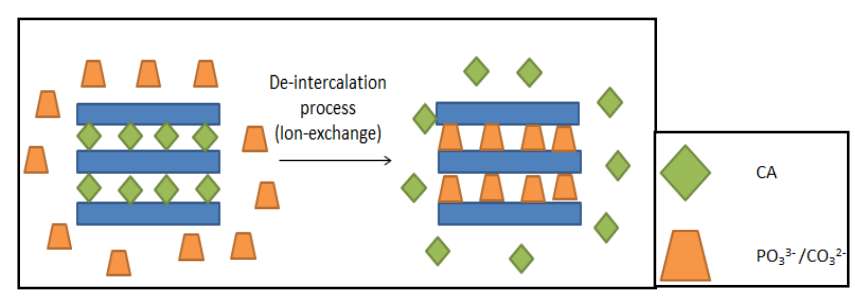

Figure 6. Illustration on the formation of new type of nanocomposites through ion-exchange process

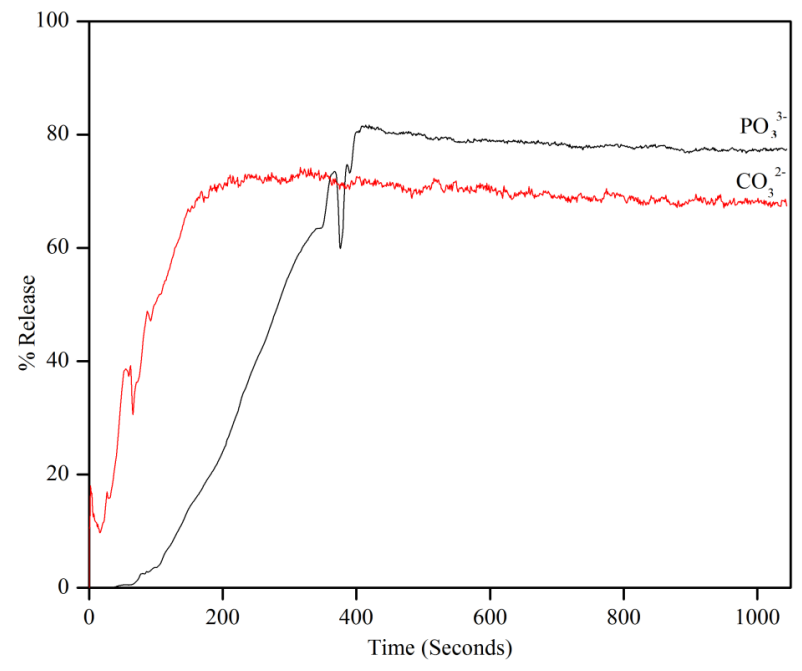

Figure 7. Sustained Release Profile of CA using $0.1 \mathrm{M}$ phosphite and carbonate anions salts 
phate influence to be much higher compare to carbonate influence. Both curve shows equilibrium state after 180 second for $\mathrm{CO}_{3}{ }^{2-}$ and 420 second for $\mathrm{PO}_{3}{ }^{3-}$ and follow by the slow release of $\mathrm{CA}$ out of the interlayer region of $\mathrm{LDHs}$ structure. Besides that, the release rate of the anion out from the LDHs matrix were being controlled by rigidity of the layers and the diffusions length, which explained limited releasing amount of $\mathrm{CA}$ out from the $\mathrm{LDHs}$ matrix for both salts anions conditions [17]. Nonetheless, the release of CA out from the interlayer region still in small portion compare to the direct application of $\mathrm{CA}$

\section{Conclusions}

The effect of concentration plays major roles for the guest anion to replace the existed anion which are nitrate. In both FTIR and PXRD pattern of $0.07 \mathrm{M} \mathrm{CA}$ shows that the $\mathrm{CA}$ are started to replaced nitrate. Thus, the concentration were increased up to $0.4 \mathrm{M}$ and the presence of new generation peak in FTIR-ATR such as at $3381 \mathrm{~cm}^{-1}$ for $\mathrm{OH}$ group, $1641 \mathrm{~cm}^{-1}$ for $\mathrm{C}=\mathrm{O}$ group, $1543 \mathrm{~cm}^{-1}$ for $\mathrm{C}=\mathrm{C}$ group and $1206 \mathrm{~cm}^{-1}$ for, $\mathrm{C}-\mathrm{O}$ and increases in basal spacing from $9.0 \AA$ to $18.0 \AA$ in basal spacing in 0.4 $\mathrm{M} \mathrm{Zn/Al-LDH-CA}$ stipulate that the intercalation were successful.. The calculated percentage of intercalated CA found in between the interlayer region was $40 \%$ reaffirmed that $\mathrm{CA}$ being intercalated in between the $\mathrm{LDH}$ interlayer structure. The nanohybrids were thermally stable state and changes in morphology structure reaffirmed successful intercalations. Controlled release was successful and depending on electron affinity, where $\mathrm{PO}_{3}{ }^{3-}$ higher than $\mathrm{CO}_{3}{ }^{2-}$ with $80 \%$ release and still in slow release manner. Throughout the observations, the intercalations were successful using $0.4 \mathrm{M}$ $\mathrm{CA}$ anion concentration with slow release formulation under different salt solutions.

\section{Acknowledgment}

The authors thank Fundamental Research Grant Scheme (FRGS/1/2016/STG01/UITM/ $02 / 4$ ) for the financial support. The gratitude also apply to Universiti Teknologi MARA (UiTM) and Nuclear Agency Malaysia for facilities that been provided.

\section{References}

[1] Holick, M.F. (2004). Sunlight and Vitamin D for Bone Health and Prevention of Autoimmune Diseases, Cancers, and Cardiovascular Disease. American Society for Clinical Nutrition, 80: 1678-1688
[2] Khan, S.B., Liu, C., Jang, E.S.,. Akhtar, K., Han, H. (2011) Encapsulation of organic UV ray Absorbents into Layered Double Hydroxide for Photochemical Properties. Materials Letters, 65: 2923-2926

[3] Marto, J., Gouveia, L.F., Chiari, G., Paiva, A., Isaac, V., Pinto, P., Simões, P., Almeida, A.J., Ribeiro, H.M. (2016). The Green Generation Of Sunscreens: Using Coffee Industrial Sub-Products, Industrial Crops and Products, 80: $93-100$

[4] Perioli, L., Nocchetti, M., Ambrogi, V., Latterini, L., Rossi, C., Costantino, U. (2008). Sunscreen immobilization on ZnAlhydrotalcite for new cosmetic formulations," Microporous Mesoporous Mater. 107(1-2): 180-189.

[5] Asiabi, H. Yamini, Y., Shamsayei, M. (2017). Highly Selective and Efficient Removal of Arsenic(V), Chromium(VI), and Selenium(VI) Oxyanions by Layered Double Hydroxide Intercalated with Zwitterionic Glycine. Journal of Hazardaous Material, 339: 239-247

[6] Bi, X., Zhang, H., Dou, L. (2014). Layered Double Hydroxide-Based Nanocarriers for Drug Delivery. Pharmaceutics, 6: 298-332

[7] El Hassani, K., Beakou, B.H., Kalnina, D., Oukani, E., Anouar, A. (2017). Effect of Morphological Properties of Layered Double Hydroxides on Adsorption of Azo Dye Methyl Orange: A Comparative Study. Applied Clay Science, 140: 124-131

[8] He, Q., Yin, S., Sato, T. (2004). Synthesis and Photochemical Properties of Zinc - Aluminum Layered Double Hydroxide / Organic UV ray Absorbing Molecule / Silica Nanocomposites. Journal of Physics and Chemistry of Solids, 65: 395-402

[9] Barahuie, F., Hussein, M.Z., Fakurazi, S., Zainal, Z. (2014). Development of Drug Delivery Systems Based on Layered Hydroxides for Nanomedicine. International Journal of Molecular Science, 15: 7750-7786.

[10] Peng, C., Dai, J., Yu, J., Yin, J. (2015). Intercalation of P-Methycinnamic Acid Anion into Zn-Al Layered Double Hydroxide to Improve UV Aging Resistance of Asphalt. AIP Advanced. 5: 1-12

[11] Djebbi, M.A., Elabed, A., Bouaziz, Z., Sadiki, M., Elabed, S., Namour, P., Jaffrezic-Renault, N., Amara, A.B.H. (2016). Delivery System for Berberine Chloride based on the Nanocarrier ZnAl-Layered Double Hydroxide: Physicochemical Characterization, Release Behavior and Evaluation of Anti-Bacterial Potential. International Journal of Pharmaceutics, 515: 422-430

[12] Kumar, H., Sangwan, P. (2013). Synthesis and Characterization of $\mathrm{MnO}_{2}$ Nanoparticles 
using Co-precipitation Technique. International Journal of Chemistry and Chemical Engineering, 3: 155-160

[13] Bashi, A.M., Haddawi, S.M., Dawood, A.H. (2011). Synthesis and Characterizations of Two Herbicides with Zn/Al Layered Double Hydroxide Nanohybrides. Journal of Kerbala Univiversity, 9: 9-16

[14] Cursino, A.C.T., Lisboa, S., Pyrrho, S., Pereira, V., Sousa, D., Wypych, F. (2013). Layered Double Hydroxides Intercalated with Anionic Surfactants / Benzophenone as Potential Materials for Sunscreens. Journal of Colloid and Interface Science, 397: 88-95

[15] Melánová, K., Kovář, P., Beneš, L., J. Svoboda, J., Veteška, M., Pospíšil, M., Zima, V. (2015). Intercalation of 1,n-diols into strontium phenylphosphonate: How the shape of the host layers influences arrangement of the guest molecules. Journal of Colloid and Interface Science., 460: 181-188

[16] Ghazali, S.A.I.S.M., Hussein, M.Z., Sarijo, S.H. (2013). 3,4-Dichlorophenoxyacetate Interleaved into Anionic Clay for Controlled Release Formulation of a New Environmentally Friendly Agrochemical. Nanoscale Research Letter, 8: 1-8

[17] Gao, X., Chen, L., Xie, J., Yin, Y., Chang, T., Duan, Y., Jiang, N. (2014). In Vitro Controlled Release of Vitamin C from Ca / Al Layered Double Hydroxide Drug Delivery System. Material Science and Engineering C, 39: 56-60

[18] Mondal, S., Dasgupta, S., Maji, K. (2016). MgAl-Layered Double Hydroxide Nanoparticles for controlled release of Salicylate. Material Science and Engineering C, 68: 557-564
[19] De Oliveira, H.B., Wypych, F. (2016). Evaluation of Layered Zinc Hydroxide Nitrate and Zinc / Nickel Double Hydroxide Salts in the Removal of Chromate Ions from Solutions. Journal of Solid State Chemistry, 243: 136145

[20] Barahuie, F., Hussein, M.Z., Arulselvan, P., Fakurazi, S., Zainal, Z. (2014). Drug Delivery System for an Anticancer Agent, Chlorogenate-Zn/Al-Layered Double Hydroxide Nanohybrid Synthesised using Direct CoPrecipitation and Ion Exchange Methods. Journal of Solid State Chemistry, 217: 31-41

[21] Sarijo, S.H., Ahmad, S.I.S.G., Mohd, M.Z. (2015). Intercalation , Physicochemical and Controlled Release Studies of OrganicInorganic-Herbicide (2,4,5 Trichlorophenoxy Butyric Acid ) Nanohybrid into HydrotalciteLike Compounds. Material Today Proceedings, 2: 345-354

[22] Chibwe, K., Jones, W. (1989). Intercalation of Organic and Inorganic Anions into the Layered Double Hydroxides. Journal of Chemistry Society, Chemistry Community, 1989: 926-927,

[23] Hashim, N., Sharif, S.N.M., Isa, I.M., Hamid, S.A., Hussein, M.Z., Bakar, S.A., Mamat, M. (2017). Controlled Release Formulation of an Anti-Depression Drug based on a LPhenylalanate-Zinc Layered Hydroxide Intercalation Compound. Journal of Physics and Chemicals Solids, 105: 35-44

[24] Hashim, N., Muda, Z., Hamid, S.A., Isa, I., Kamari, A., Mohamed, A. (2014). Characterization and Controlled Release Formulation of Agrochemical herbicides Based on ZincLayered Hydroxide-3-(4-methoxyphenyl) Propionate nanocomposites. Journal of Physics Chemicals Science, 1: 1-6

Selected and Revised Papers from The $4^{\text {th }}$ International Conference of Chemical Engineering \& Industrial Biotechnology (ICCEIB 2018) (http://icceib.ump.edu.my/index.php/en/) (Universiti Malaysia Pahang, by 1st_2nd August 2018) after Peer-reviewed by Scientific Committee of ICCEIB 2018 and Peer-Reviewers of Bulletin of Chemical Reaction Engineering \& Catalysis 